\title{
Mitochondrial complex I activity is impaired during HIV-1-induced T-cell apoptosis
}

\author{
JS Ladha ${ }^{1}$, MK Tripathy ${ }^{1}$ and D Mitra*,1 \\ ${ }^{1}$ National Centre for Cell Science, Ganeshkhind, Pune 411007, India \\ * Corresponding author: D Mitra, National Centre for Cell Science, Pune \\ University Campus, Ganeshkhind, Pune 411007, India. \\ Tel: +91-20-25690931; Fax: +91-20-25692259; \\ E-mail: dmitra@nccs.res.in, dmitra01@yahoo.co.in
}

Received 20.9.04; revised 11.4.05; accepted 12.4.05; published online 20.5.05 Edited by M Piacentini

\begin{abstract}
Studies carried out till date to elucidate the pathways involved in HIV-1-induced T-cell depletion has revealed that apoptosis underlie the etiology, however, a clear molecular understanding of HIV-1-induced apoptosis has remained elusive. Although evidences pointing towards the importance of mitochondrial energy generating system in apoptosis exist but it's exact role remains to be clearly understood. Here, we describe for the first time specific downregulation of a complex I subunit NDUFA6 with simultaneous impairment of mitochondrial complex I activity in HIV infection. We also show that NDUFA6 gene silencing induces apoptosis and its overexpression reduces apoptosis in HIV-infected cells. Finally, sensitivity to complex I inhibitor Rotenone is reduced in HIV-1-infected T cells indicating an important role for it in the death process. Our data provide a novel molecular basis as to how the virus might interfere with host cell energy generating system during apoptotic cell death.

Cell Death and Differentiation (2005) 12, 1417-1428.

doi:10.1038/sj.cdd.4401668; published online 20 May 2005
\end{abstract}

Keywords: apoptosis; HIV-1; mitochondria; NDUFA6; complex I

Abbreviations: $\Delta \Psi_{\mathrm{m}}$, mitochondrial transmembrane potential; ADP, adenosine 5'-diphosphate; ATP, adenosine 5'-triphosphate; AZT, azidothymidine; BN-PAGE, blue native-polyacrylamide gel electrophoresis; COX-4, cytochrome oxidase-4; ELISA, enzyme-linked immunosorbent assay; ETC, electron transport chain; GFP, green fluorescent protein; HIV-1, human immunodeficiency virus-1; IL-2, interleukin-2; LTR, long terminal repeat; MACS, magnetic cell sorting; MOI, multiplicity of infection; MTT, 3-[4,5-dimethylthiazol-2-yl]-2,5-diphenyl tetrazolium bromide; PARP, poly-ADP ribose polymerase; PBMC, peripheral blood mononuclear cells; PCR, polymerase chain reaction; PS, phosphatidyl serine; ROS, reactive oxygen species

\section{Introduction}

Human immunodeficiency virus-1 (HIV-1) infection comprises of multistep and multifactorial processes, which depends on a number of viral and cellular factors and is accompanied by complex and dynamic changes in the patterns of gene expression. One of the hallmarks of HIV infection is gradual decline of CD4 + T cells in the peripheral blood both due to HIV-mediated cell killing and retrafficking of the cells to the lymphoid tissues and other organs. Several mechanisms have been proposed to account for the functional and quantitative loss of $T$ cells, which include apoptosis, direct lysis by virus infection, necrosis, syncytium formation, anergy caused due to inappropriate signaling, autoimmunity, virusspecific immune response, super antigen-mediated deletion, upregulation of FasL- and activation-induced cell death. ${ }^{1-5}$ Despite evidences for all these pathways by which HIV can induce cell death, apoptosis has been the major focus of research implicated in HIV-induced T-cell loss. ${ }^{6-8}$ Various viral proteins such as Tat, Nef, Vpr, protease, and gp120 have also been individually implicated in initiation and/or intensification of the death process by regulating the apoptotic pathway. ${ }^{2,6,7}$ Nonetheless, the work performed in last few years suggest that the connections between HIV-1 and apoptosis induction are highly complex, involving multiple viral genes and diverse signaling pathways and could occur in both infected and uninfected bystander cells. ${ }^{9,10}$

Mitochondria is central to the apoptotic death process since it not only plays an important role in generating ATP, the energy driving force of the cell, but also has numerous other functions, disturbance of any of which poses a threat on the survival of the cell. ${ }^{11,12}$ In particular, both the extrinsic and intrinsic pathways of apoptotic cell death ultimately converge into the mitochondria and then proceed via a common downstream pathway. ${ }^{13}$ Mitochondrial functions including protein import, ATP generation and lipid biosynthesis are all dependent on the proper maintenance of the mitochondrial transmembrane potential $\left(\Delta \Psi_{\mathrm{m}}\right)$, loss of which could lead to cell death. ${ }^{14-16}$ In addition, mitochondrial production of reactive oxygen species (ROS) also appears to play a role in cell death. ${ }^{17}$ Recent evidences show that HIV-1 modulates the energy generating system of the host cells thereby leading them towards death. ${ }^{18}$ Ample clinical evidences of mitochondrial toxicity are also available to show that HIV-1 targets the powerhouse of the cell affecting mitochondrial DNA and protein. ${ }^{18}$ Increased production of ROS in productively infected CD4 $+\mathrm{T}$ cells as well as HIV-infected individuals has been also reported in the literature. ${ }^{14,19}$ It has been demonstrated that caspases require ATP to perform their effector function; ${ }^{18,20}$ however, decrease in ATP levels up to certain extent has also been noted in apoptotic cell death. ${ }^{21}$ More recently it has been shown that the rapid loss of $\Delta \Psi_{\mathrm{m}}$ and the generation of ROS occurring during cell death are because of the effects of activated caspases on mitochondrial electron transport complexes. ${ }^{22,23}$ All these evidences point towards the importance of mitochondrial energy generating system in apoptotic cell death, however, a clear molecular understanding of the process remains to be achieved. ${ }^{17}$

Previous studies to analyze gene expression in HIV-1infected cells has been carried out using mixed populations of 
infected cells and comparing the global gene expression with uninfected controls using different techniques like differential display, serial analysis of gene expression, subtractive hybridization and microarray. ${ }^{24-28}$ One of the studies using microarray, has clearly demonstrated marked changes in transcription of genes those may be essential for mitochondrial function and integrity, and DNA repair mechanisms directly leading to the induction of apoptosis. ${ }^{27}$ Studies have also indicated a general decrease in majority of the metabolic enzymes upon HIV-1 infection. ${ }^{28}$ HIV-1 infection has also been implicated to result in respiratory insufficiency and in general interference with oxidative metabolism, generating ROS and thus leading to apoptotic cell death. ${ }^{25}$ Visualizing gene expression changes in purified population of cells is necessary to realize the subtle changes in gene expression modulated by HIV-1 and correlate induced changes with the observed phenotype. Based on differential gene expression analysis of isolated apoptotic cells, we report here specific downregulation of mitochondrial complex I subunit NDUFA6 with simultaneous impairment of complex I activity in HIV-induced T-cell apoptosis. Although the impairment of oxidative phosphorylation system has been earlier associated with apoptosis, to the best of our knowledge this is the first report of downregulation of complex I in HIV-induced apoptotic cell death.

\section{Results}

\section{HIV-1 induces apoptosis in both infected and bystander CEM-GFP cells}

In order to visualize the death of infected cells in HIV-1 infection, we have used a human reporter T-cell line CEMGFP in the present study, which shows bright green fluorescence on infection due to Tat-mediated transactivation of GFP expression driven by HIV-1 long terminal repeat (LTR) promoter. ${ }^{29}$ Although this cell line has previously been shown to undergo apoptosis upon HIV-1 infection, ${ }^{27}$ we reconfirmed induction of apoptosis by a number of assays. In order to establish the process of HIV-induced apoptosis in the CEMGFP reporter T-cell line and to identify the time point for apoptotic cell isolation, we analyzed mock- and HIV-1 NL4.3infected cells for infection by GFP fluorescence and apoptosis induction at regular intervals by phycoerythrin (PE)-Annexin $V$ staining using flow cytometry (Table 1). There was a gradual increase in the PE-Annexin-positive cells up to day 9 after which the cell death seems to become stabilized. About $30 \%$ cells were found to be Annexin positive on day 9, the dot plot of which is shown in Figure 1a. It also shows the presence of Annexin staining in both, infected and uninfected cells based on GFP fluorescence, which provides a direct evidence for induction of apoptosis in both infected and uninfected bystander cells. ${ }^{1}$ Its worth mentioning here that apoptosis was not observed in $5 \mu \mathrm{M}$ azidothymidine (AZT), a reverse transcriptase inhibitor, treated infected cells (data not shown). Furthermore, we analyzed the infected cells for a number of well-characterized apoptotic hallmarks like the presence of DNA laddering, release of cytochrome $c$ from mitochondria and cleavage of poly-ADP ribose polymerase (PARP). As shown in Figure 1b, apoptotic hallmark of DNA laddering is clearly evident in infected cells as compared to mock-infected cells. Then we isolated mitochondria and cytosolic fraction from the mock or infected cells, purity of which was checked by immunoblotting for cytochrome oxidase-4 (COX-4). Immunoblotting for cytochrome $c$ with these two fractions clearly show that it is depleted in mitochondrial fraction with concomitant increase in the cytosol (Figure 1c). Furthermore, when mock-infected and infected cell lysates were probed for cleaved PARP, it was clearly observed that HIV-1 infection induces cleavage of PARP as compared to the mock-infected cells (Figure 1d). All these results clearly point towards the induction of apoptosis upon HIV-1 infection in CEM-GFP cells and provide a model system for separating infected cells into apoptotic and nonapoptotic cells.

\section{Isolation of apoptotic cells using Annexin-coated magnetic beads}

In order to study subtle changes in gene expression of HIVinduced apoptotic cells, we have performed mRNA differential display with relatively pure population of cells obtained by magnetic bead-based cell sorting. Apoptotic cells were isolated from HIV-infected CEM-GFP cell population on day 9 using Annexin-coated magnetic beads. Two rounds of selection were performed to yield more than $90 \%$ pure apoptotic and nonapoptotic cell populations (Figure 2). The unbound cells, which are nonapoptotic, were pooled and were used as control for the apoptotic cells. As expected from the flow cytometry data (Figure 1a), both intracellular p24 antigen assay and HIV-1 gag-specific polymerase chain reaction (PCR) indicated the presence of HIV-1 infection in both

Table 1 Temporal analysis of progression of HIV-1 infection by GFP fluorescence, viral load (p24 antigen), apoptosis induction and NDUFA6 expression in NL4.3infected CEM-GFP cells

\begin{tabular}{|c|c|c|c|c|}
\hline Days (postinfection) & $\begin{array}{l}\text { GFP (mean } \\
\text { fluorescence) }\end{array}$ & $\begin{array}{l}\text { p24 concentration } \\
(\mathrm{ng} / \mathrm{ml})\end{array}$ & $\begin{array}{c}\% \text { apoptosis (PE- } \\
\text { Annexin-positive cells) }\end{array}$ & $\begin{array}{l}\text { Fold decrease (NDUFA6 } \\
\text { gene expression) }\end{array}$ \\
\hline 1 & 105.14 & 0.23 & 11.17 & 0.1 \\
\hline 3 & 537.95 & 8 & 14.6 & 0.4 \\
\hline 5 & 740.09 & 45 & 17.49 & 1.32 \\
\hline 7 & 1008.82 & 110 & 20.08 & 3.03 \\
\hline 9 & 1513.87 & 230 & 29.87 & 5.27 \\
\hline 11 & 1117.62 & 85 & 26.04 & 4.5 \\
\hline
\end{tabular}

The CEM-GFP infection was performed as described in Materials and Methods. GFP fluorescence and PE-Annexin staining was monitored by flow cytometry. Virus production was measured by p24 antigen capture ELISA. NDUFA6 expression was quantified by real-time PCR as described in the text. 
a
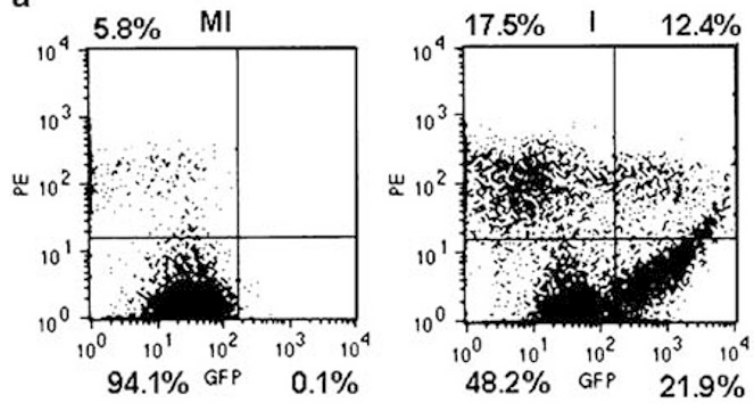

C

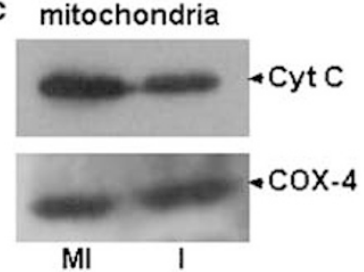

Cytosol

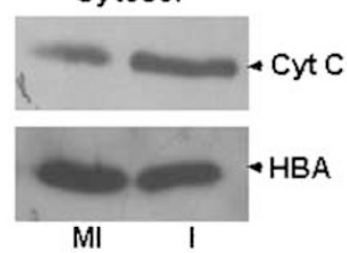

b

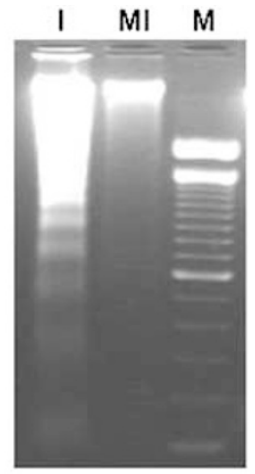

d

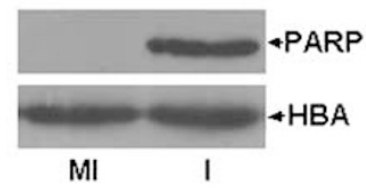

Figure 1 HIV-1 infection induces apoptosis in CEM-GFP T cell line. CEM-GFP reporter T-cell line was infected with HIV-1 NL4.3 isolate at 0.1 MOI followed by analysis of apoptotic cell death in mock-infected (MI) and infected (I) cells by various methods. (a) Flow cytometric analysis of CEM-GFP cells at 9th day postinfection for PEAnnexin staining and GFP fluorescence. (b) Visualization of DNA fragmentation in HIV-1-infected CEM-GFP cells. M, Mol. Size marker. (c) Immunoblotting of cytochrome $c$ in mitochondria and cytosolic fraction of HIV-infected CEM-GFP cells. COX-4 (cytochrome oxidase-4) was used as an internal control for mitochondria and HBA (human $\beta$-actin) for cytosol. (d) Immunoblotting of cleaved PARP from infected CEM-GFP cell lysate. HBA (human $\beta$-actin) was used as a loading control

apoptotic and nonapoptotic cells (data not shown). Thus the isolated populations of cells provide an elegant model system for identification of differentially modulated genes in apoptosis induced due to HIV infection.

\section{NDUFA6 expression and mitochondrial complex I activity is downregulated in HIV-induced apoptosis}

Differential expression of genes in the apoptotic and nonapoptotic population of cells was analyzed by mRNA differential display technique ${ }^{30}$ as described in experimental procedures. One of the genes reproducibly found to be downregulated by differential display in HIV-1-infected apoptotic cells was NDUFA6, (CIB14), a nuclear encoded 14$15 \mathrm{kDa}$ subunit of mitochondrial complex I (NADH dehydrogenase). ${ }^{31}$ As the functional importance of this subunit of complex I is not well characterized and also to identify whether there is a global downregulation of other subunits of multisubunit complex I as well, we looked into the expression pattern of two other subunits. Reverse transcription-polymerase chain reaction (RT-PCR) analysis of RNA isolated from apoptotic and nonapoptotic cells confirmed the downregulation of NDUFA6, whereas no change in expression level was observed in two randomly chosen subunits from 46-subunit complex I, ${ }^{32}$ one nuclear encoded subcomplex 6 (NDUFB6) and another subunit ND2 encoded by mitochondria (Figure 3a). In order to see whether this downregulation could be seen in unsorted infected cells, RT-PCR was also performed with RNA made from mock-infected and NL4.3infected CEM-GFP cells. Human peripheral blood mononuclear cells (PBMC) infected with NL4.3 and undergoing apoptotic cell death was also analyzed for NDUFA6 expression. The downregulation of NDUFA 6 was observed not only in RNA isolated from infected CEM-GFP cells (data not shown) but was also seen in HIV-1 NL4.3-infected human PBMCs as compared to mock-infected cells (Figure $3 b$ ) suggesting thereby its potential importance in AIDS pathogenesis. Similar results were also obtained with CEM-GFP cells infected with IIIB virus isolate (Supplementary data, Figure S1) indicating it to be not a viral isolate-specific phenomenon. These data also suggest that some kind of specificity is involved in the downregulation of complex I subunit NDUFA6 as no change is observed with NDUFB6 and ND2 expression. Quantitation of NDUFA6 expression by realtime PCR of the same RNA used in Figure $3 a$ and $b$ indicates about eight- and 2.3-fold downregulation in sorted apoptotic CEM-GFP and infected PBMCs, respectively (Figure 3c). As the downregulation of NDUFA6 was visible in unsorted infected cells, all the experiments henceforth was performed using unsorted mock-infected and NL4.3-infected CEM-GFP cells. We then analyzed NDUFA6 gene expression in NL4.3infected CEM-GFP cells by real-time PCR at different days postinfection and compared them with percentage of Annexinpositive cells and viral load as indicated by GFP fluorescence and p24 concentration at those time points. The results presented in Table 1 clearly points towards a temporal relationship between NDUFA6 expression and HIV-1-induced apoptotic cell death. Next, we wanted to see whether transcriptional downregulation of the NDUFA6 leads to lower protein level in the infected cells. Immunoblot analysis of mitochondria isolated from mock-infected and infected CEMGFP cells clearly showed a downregulation of NDUFA6 at the protein level in infected cells that was absent in AZT-treated infected cells (Figure $3 d$ ). Again, no change was observed in 
a
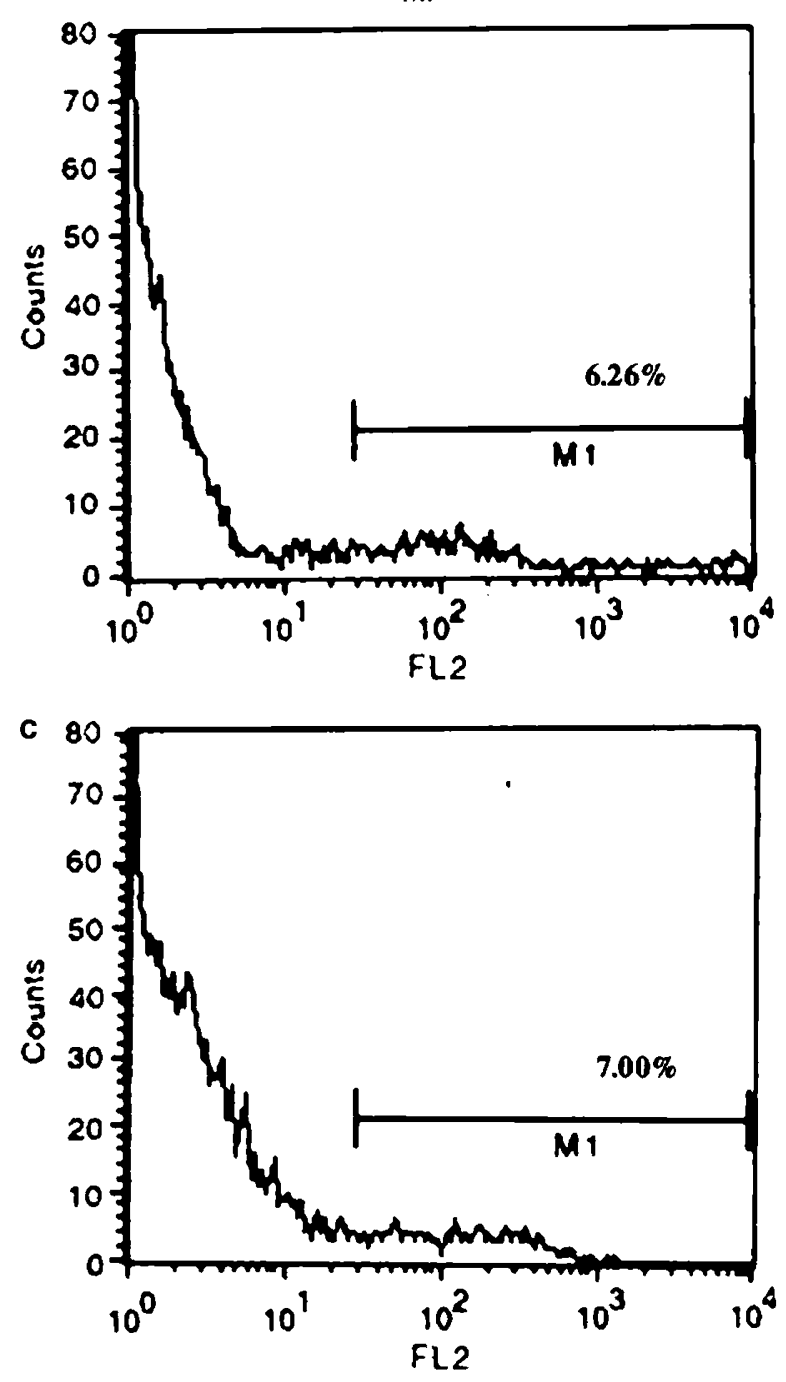

NAp b
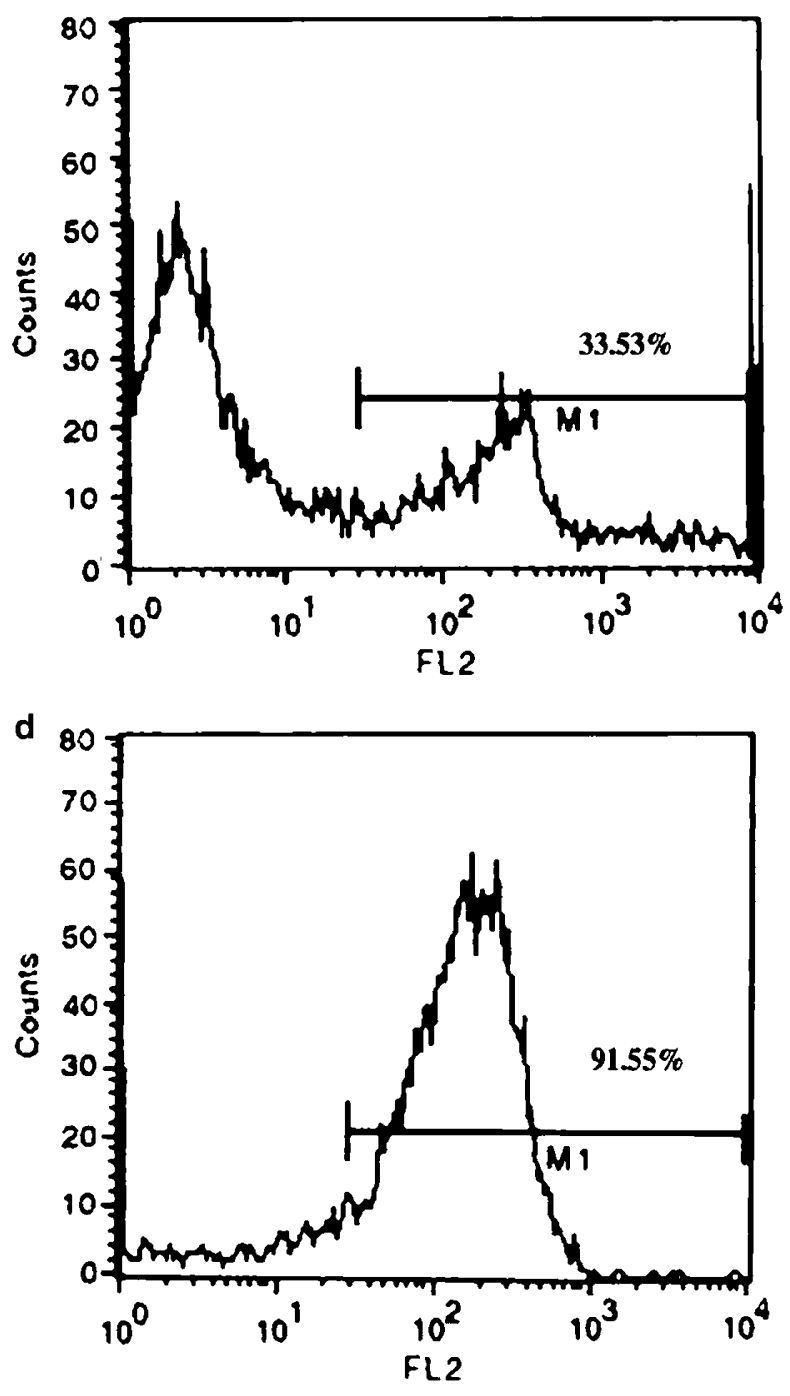

Ap

Figure 2 Histograms showing PE-Annexin-staining profile before and after isolation of apoptotic cells using Annexin V-coated magnetic beads. About $5 \times 10^{7} \mathrm{CEM}$ GFP-infected cells ( 9 day postinfection) were used for isolation of apoptotic cells. The cells were subjected to two rounds of binding and elution on Annexin-coated magnetic beads (Miltenyi Biotec, Germany). Pre- and post- MACS selected cells were stained with PE-Annexin and visualized by flow cytometry. (a) Mock-infected cells (MI). (b) HIV-1-infected cells (I) prior to selection. (c) Negatively selected nonapoptotic population (NAp) from HIV-1-infected cells. (d) Positively selected apoptotic population (Ap) from HIV-1-infected cells

NDUFB6 subunit expression thereby suggesting this downregulation to be a subunit-specific phenomenon.

We then analyzed whether changes in expression level of NDUFA6, leads to any change in the activity of multisubunit complex I. As shown in Figure 4a, a distinct three-fold inhibition of rotenone-sensitive mitochondrial complex I activity is observed in HIV-1-infected CEM-GFP cells. Blue Native polyacrylamide gel electrophoresis (BN-PAGE) combined with in-gel activity staining is a reliable method to resolve and assess the mitochondrial electron transport chain complexes activity in their native forms. ${ }^{33}$ Complex I activity staining along with Coomassie blue staining was then performed by the in-gel-staining method using mitochondria isolated from mock-infected, infected and AZT-treated infected cells. As shown in Figure $4 \mathrm{~b}$ and $\mathrm{c}$, it is clear that the complex I activity is decreased in NL4.3-infected CEMGFP mitochondrial sample as compared to AZT-treated infected and mock-infected samples. These data clearly point towards impairment of complex I activity during HIV-1 infection.

\section{NDUFA6 plays an important role in HIV-induced apoptosis}

As the above results points toward a very important role for NDUFA6 in HIV-induced apoptosis, we wanted to see whether NDUFA6 overexpression in infected cells could lead to inhibition of apoptosis. As Jurkat cells are transfected more 


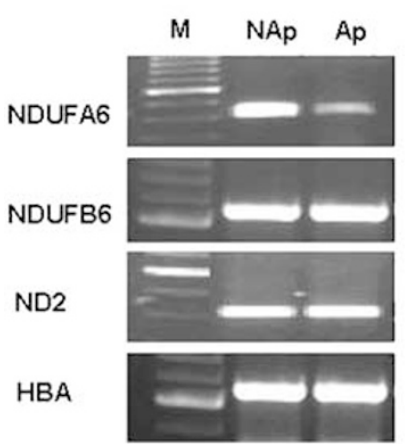

b

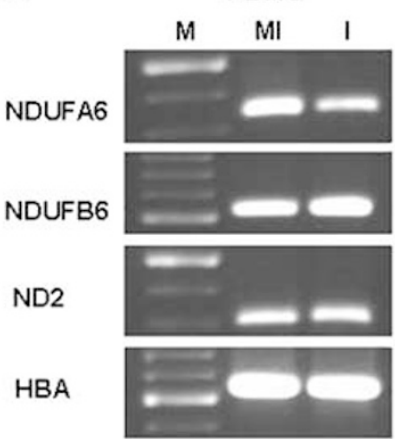

C

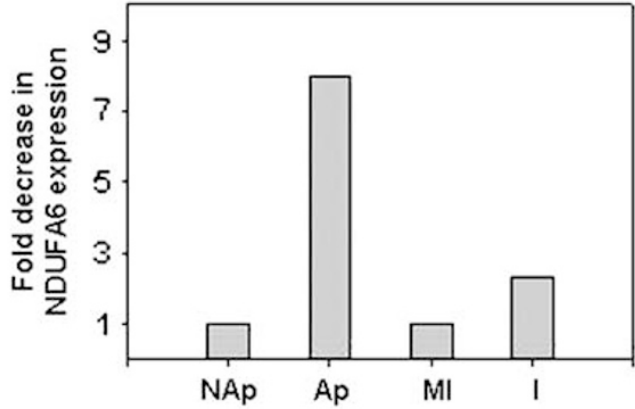

d

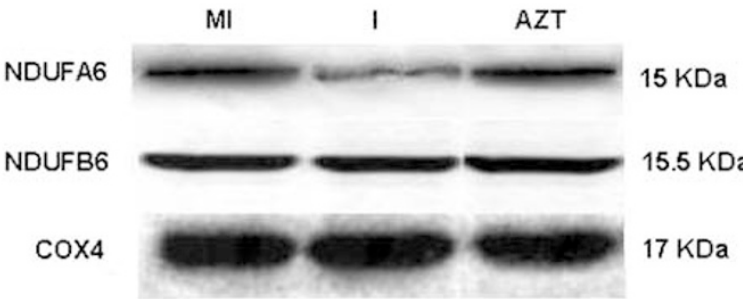

Figure 3 NDUFA6 expression is downregulated in HIV-1-induced apoptosis. (a) Expression of mitochondrial complex I subunits NDUFA6, NDUFB6 and ND2 in purified apoptotic and nonapoptotic CEM-GFP cells infected with NL4.3 virus using RT-PCR. RNA was isolated from the purified apoptotic (Ap) and nonapoptotic (NAp) cells (day 9 postinfection) followed by RT-PCR using genespecific primers as listed in Materials and Methods. Human $\beta$-actin was used as an internal control. M, Mol. Size marker. (b) Expression of mitochondrial complex I subunits NDUFA6, NDUFB6 and ND2 in HIV-1-infected PBMCs using RT-PCR. RNA was isolated from the mock-infected and HIV-1 NL4.3-infected PBMCs (day 7 postinfection) followed by RT-PCR using gene-specific primers as described earlier. The infected PBMCs used for RNA isolation showed about $32 \%$ apoptosis by PE-Annexin staining. Human $\beta$-actin was used as an internal control. M, Mol. Size marker. (c) Analysis of NDUFA6 expression by quantitative real-time PCR. Quantitation of NDUFA6 expression in RNA samples used in (a) and (b) was performed as described in Materials and Methods. NAp nonapoptotic CEM-GFP; Ap, apoptotic CEM-GFP; Ml, mock-infected PBMC; I, infected PBMC. (d) Western blot analysis of NDUFA6 and NDUFB6 expression in mitochondrial fractions of HIV-1-infected CEM-GFP cells. MI, mock infected; I, NL4.3 infected; AZT, AZT-treated NL4.3 infected. COX-4 was used as an equal loading control for mitochondrial lysates

efficiently than CEM-GFP, we performed transfection experiments with Jurkat cells. Prior to that, similar induction of apoptosis and downregulation of NDUFA6 upon HIV-1 NL4.3 virus infection was confirmed in Jurkat cells again emphasizing this to be not a cell type-specific phenomenon (Figure $5 \mathrm{a}$ and $b$ ). We then transfected p-TARGET-NDUFA6 in NL4.3infected Jurkat cells 3rd day postinfection and monitored apoptosis and NDUFA6 expression after about $40 \mathrm{~h}$ (5th day a
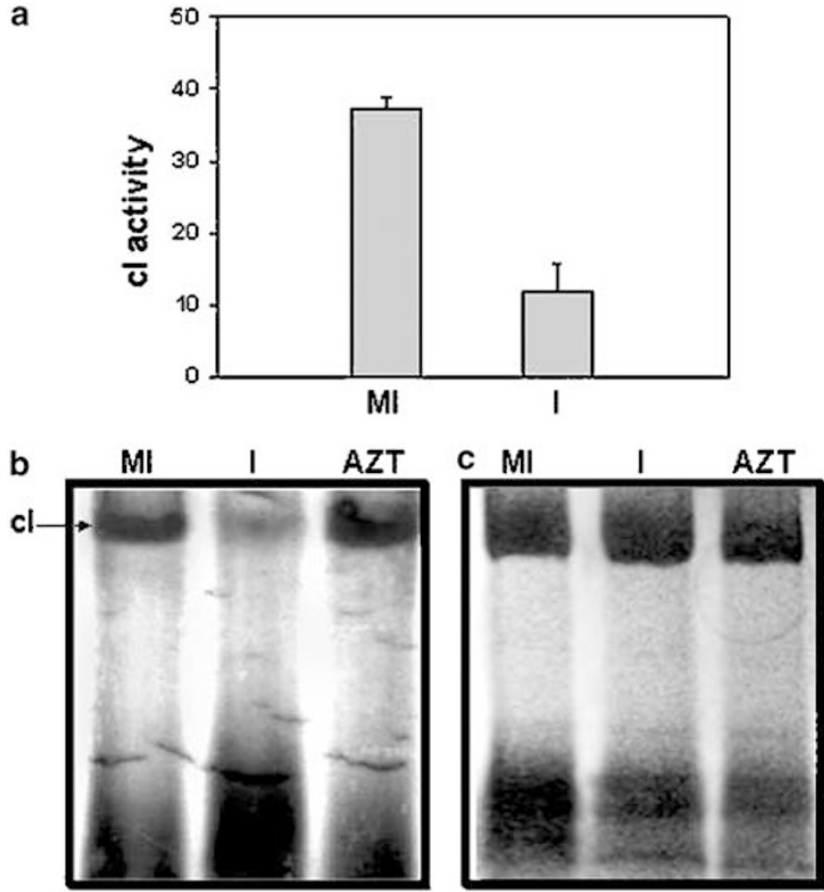

Figure 4 Mitochondrial complex I activity is downregulated in HIV-1-induced apoptosis. (a) Biochemical analysis of rotenone-specific NADH dehydrogenase (complex I) activity in mitochondria isolated from mock- and HIV-1 infected CEMGFP cells as described in Materials and Methods. The activity is shown as a mean of three independent experiments. Ml, mock infected and I, infected. (b) Mitochondrial proteins were resolved on $5-12 \%$ native polyacrylamide gradient gel and complex I-specific activity staining was performed in the gel as described in the text. MI, mock infected; I, NL4.3 infected; AZT, AZT-treated NL4.3-infected sample. (c) Coomassie blue staining of the same gel used above (Figure 4b) prior to complex I activity staining to show equal mitochondrial protein loading in the gel

postinfection). As shown in Figure $5 \mathrm{a}$, increasing number of apoptotic cells were observed in untransfected infected cells on days 3 and 5 postinfection, which showed significant reduction on day 5 in NDUFA6-transfected infected cells. These apoptosis data correlate very well with NDUFA6 expression levels (Figure 5b), where NDUFA6 downregulation is clearly evident in infected untransfected cells but its expression is significantly increased in the transfected cells after $40 \mathrm{~h}$, again confirming that NDUFA6 overexpression can reduce HIV-induced apoptosis.

To further assess the importance of NDUFA6 in apoptosis induction, loss of function experiment using specific SiRNA duplexes (Dharmacon, USA) were performed in Jurkat cells. As seen clearly in the Figure $5 c$, there was a time-dependent decrease in the NDUFA6 levels in the cells transfected with smart pool SiRNA duplex (lanes 2-4) as compared to the control siRNA duplex (lane 1). To verify the RT-PCR results, cDNA from SiRNA transfected Jurkat cells were analyzed for fold difference in the expression levels of the NDUFA6 gene with respect to human $\beta$-actin control by real-time PCR measurement. In contrast to the mock- and control SiRNAtransfected cells, clear three-fold decrease in NDUFA6 expression was observed in NDUFA6 Smartpool-transfected cells at $72 \mathrm{~h}$ post-transfection (Figure $5 \mathrm{~d}$ ). This decrease in the NDUFA6 levels in the Smartpool SiRNA-transfected cells 
resulted in induction of apoptosis as observed by cells staining positive for Annexin $\mathrm{V}$ binding (Figure 5e). All these data clearly indicate that inhibition of NDUFA6 expression leads to induction of apoptosis and overexpression of NDUFA6 can rescue HIV-induced apoptosis.

\section{Role of complex I in HIV-induced apoptosis}

Although the role of mitochondrial complex I in apoptosis has not been clearly elucidated but its specific inhibitor rotenone has been shown to reduce cell viability by inducing apoptotic cell death. ${ }^{34,35}$ In order to elucidate the role of complex I activity in apoptosis observed in CEM-GFP cells, we have

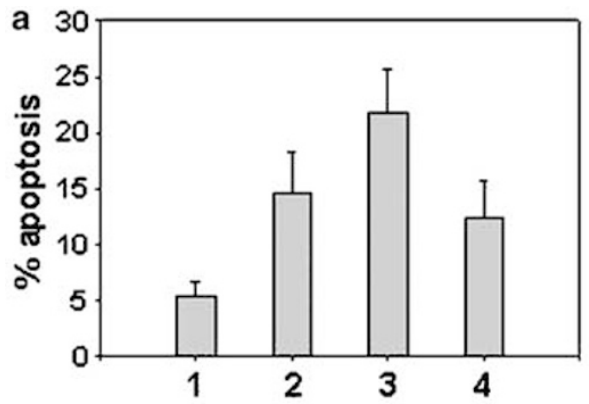

b
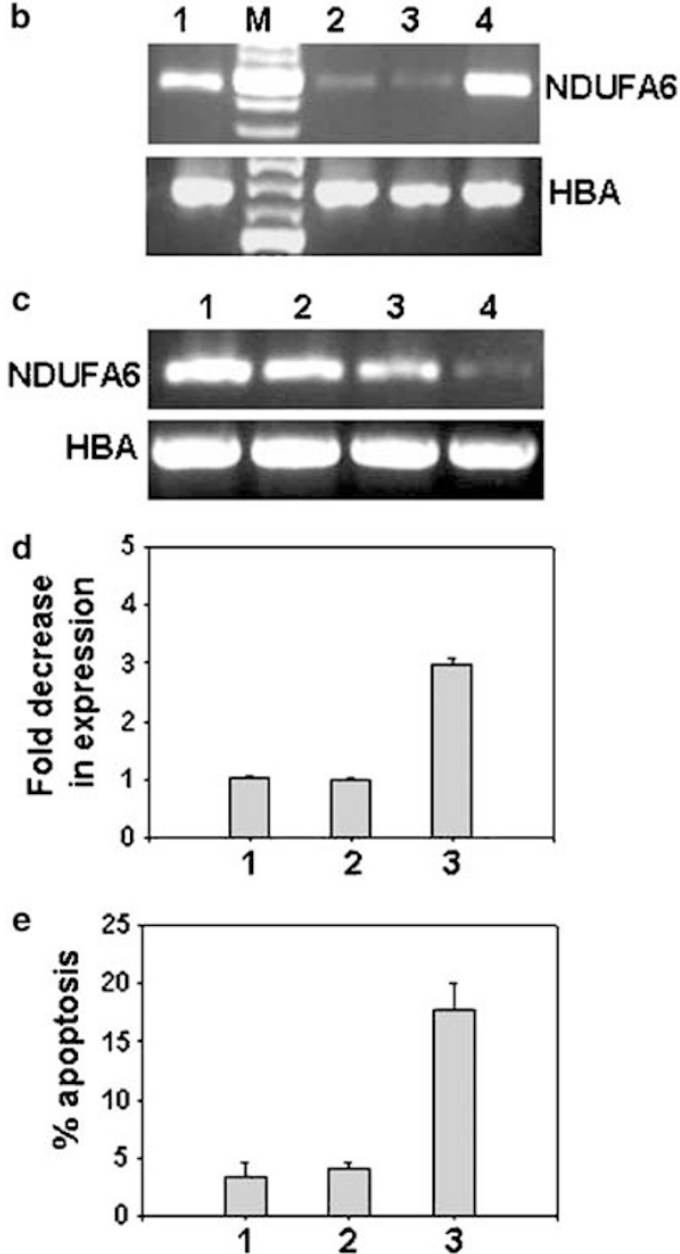

used the specific inhibitor rotenone. Treatment of CEM-GFP cells with rotenone clearly induces apoptotic cell death as is evident from PE-Annexin staining and DNA laddering experiments (Figure 6a and b). We then performed an MTT (3-[4,5dimethylthiazol-2-yl]-2,5-diphenyl tetrazolium bromide) cell viability assay, which is based on oxidation-reduction reaction by cellular dehydrogenases present in viable cells, and to study the effect of specific complex I (NADH dehydrogenase) inhibitor rotenone treatment on mock- and HIV-1-infected cells. This was performed to test the hypothesis that if complex I activity is specifically inhibited by HIV-1 infection and is responsible for cell death; then rotenone-mediated inhibition of complex I activity may be reduced in HIV-1infected cell population. We tried to compare the effect of rotenone treatment on mock- and HIV-infected cells at different time points postinfection. Interestingly, HIV-1-infected cells seem to gradually become insensitive to rotenone-induced cell death, as compared to mock-infected cells (Figure $6 \mathrm{c}$ ). To further confirm that the results obtained with MTT assay is actually due to apoptosis, we have also analyzed the rotenone-treated infected cells by PE-Annexin staining followed by flow cytometry, which showed almost similar profile (Supplementary data, Figure S2). These data clearly indicate that as the complex I activity is already downregulated in HIV-1 infection, rotenone treatment is not able to further reduce the viability, much as it does with the mock infected cells. Interestingly unlike rotenone, oligomycin, a specific complex $\mathrm{V}$ inhibitor, ${ }^{34}$ also known to induce apoptosis, showed increased cell death in infected cells as compared to mock-infected cells suggesting a possible synergistic effect of infection and mitochondrial complex $\mathrm{V}$ inhibition. Then, as complex I is the first step in ATP synthetic pathway and several previous investigations have indicated the importance of ATP in apoptotic cell death, ${ }^{18}$ we quantitated and compared the ATP levels of infected cells with mock-infected cells at different days postinfection. As compared to mock-infected cells, ATP levels of infected cells showed significant reduction in the first 3 days, followed by stabilization afterwards at a reduced level (Figure 6d). This data indicates that inhibition of complex I activity leads to reduction of ATP levels in HIV-infected cells, but it does not probably lead to complete cessation of ATP synthesis.

Figure 5 NDUFA6 overexpression inhibits HIV-1-induced apoptosis whereas NDUFA6 gene silencing induces apoptosis. (a) Analysis of apoptosis by PEAnnexin staining in NL4.3-infected Jurkat cells, half of which were transfected on day 3 for NDUFA6 overexpression as detailed in Materials and Methods. 1, Mock-infected cells; 2, NL4.3-infected cells on day 3 postinfection just prior to transfection; 3, NL4.3-infected cells on day 5 postinfection; 4, NL4.3-infected cells transfected with NDUFA6 on day 3 and analyzed on day 5 postinfection. (b) Analysis of NDUFA6 expression by RT-PCR in NL4.3-infected Jurkat cells described in (a). The lane numbers also correspond to the bar numbers in (a). (c) Jurkat cells were transfected with $100 \mathrm{nM}$ of pooled SiRNA against NDUFA6 or control duplex and RT-PCR was performed for NDUFA6 and HBA at different time points post-transfection. 1, control SiRNA (72 h); 2,3,4, Smartpool reagent at 36,48 and $72 \mathrm{~h}$, respectively. (d) Real-time PCR was performed using RNA from Jurkat cells transfected with 1, mock; 2, control SiRNA and 3, Smartpool duplex against NDUFA6 and harvested after $72 \mathrm{~h}$ to assess the fold downregulation of NDUFA6 expression. (e) Jurkat cells transfected with either 1, mock; 2, SiRNA control or 3, Smartpool SiRNA reagent (NDUFA6) was harvested $72 \mathrm{~h}$ posttransfection and analyzed for apoptosis induction by staining with PE-labeled Annexin V 
Mitochondrial functions including protein import, ATP generation and lipid biogenesis depend on the maintenance of $\Delta \Psi_{\mathrm{m}}$. Impairment of complex I activity has been implicated in generation of ROS and loss of $\Delta \Psi_{\mathrm{m}}$, thereby inducing apoptosis. We then analyzed the mitochondrial transmembrane potential in mock- and HIV-1 NL4.3-infected cells by staining the cells with MitoTracker Red and observing them under confocal microscope. Dissipation of mitochondrial

a

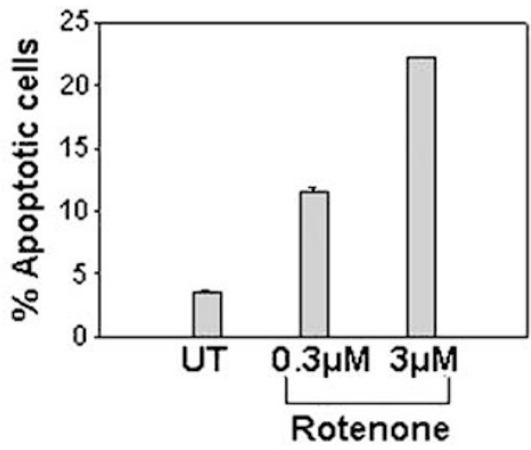

b

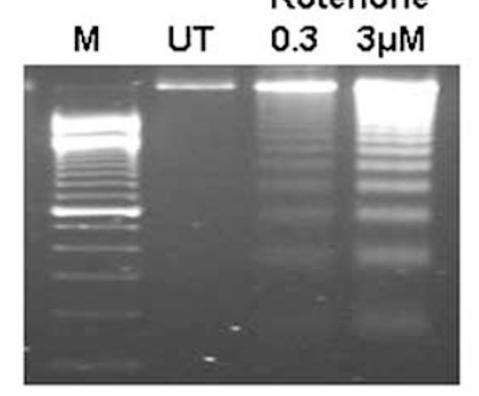

C
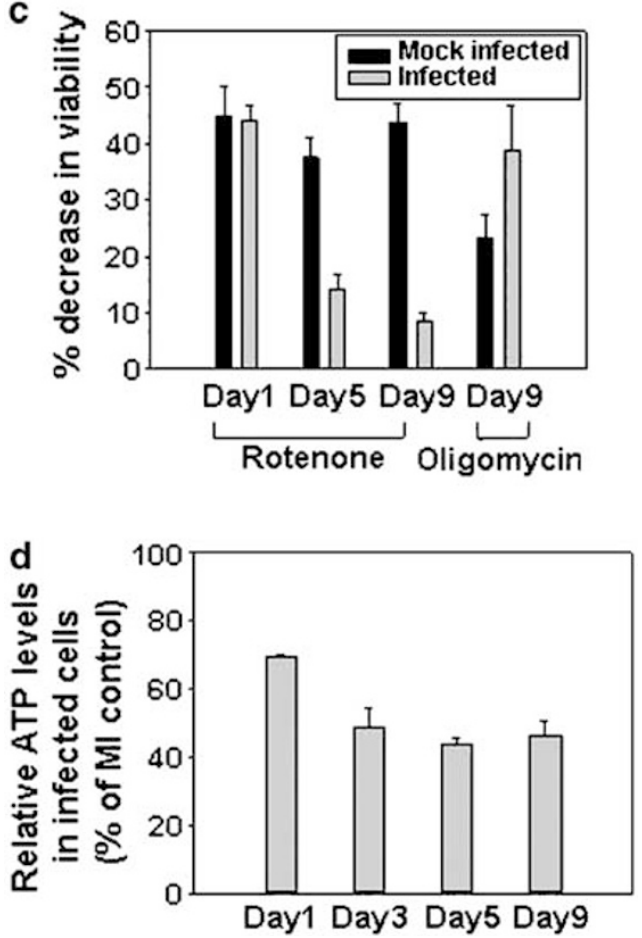

membrane potential similar to rotenone treatment was evident in the infected cells (Figure 7) as seen by reduced red (MT) fluorescence with the progression of infection (high GFP fluorescence), which was not observed in mock-infected cells. These results clearly indicate an important role for complex I in HIV-induced T-cell apoptosis.

\section{Discussion}

Extensive research carried out till date to elucidate the pathways that HIV-1 uses to induce cell death has revealed that apoptosis may underlie the etiology of T-cell depletion, however, a clear molecular understanding of HIV-1-induced apoptosis has remained elusive. Controversy still exists not only about the mechanism of cell death but also about the occurrence of apoptosis in infected or uninfected bystander cells. ${ }^{1-5}$ In the present work, we clearly demonstrate using the green fluorescence-based reporter system that HIV-1 induces apoptosis in CEM-GFP cells and it definitively occurs in both infected and uninfected bystander cells. In the present study, we have used a novel strategy to isolate apoptotic and nonapoptotic cells from the mixed population of HIV-1infected cells using magnetic beads coated with Annexin. Two rounds of selection led to more than $90 \%$ pure population of both apoptotic and nonapoptotic cells, which was used for differential gene expression analysis using mRNA differential display technique to identify subtle changes in gene expression. Mitochondrial complex I subunit NDUFA6 was reproducibly found to be downregulated in not only isolated apoptotic cells but also in HIV-1 infected CEM-GFP, Jurkat cells and PBMCs in all of which HIV infection induces apoptosis. We show specific downregulation of NDUFA6 both at the RNA and protein level with simultaneous downregulation of complex I enzymatic activity. Furthermore, a temporal correlation of NDUFA6 expression with apoptosis in HIV-1infected CEM-GFP cells is clearly indicative of the importance of this phenomenon in HIV pathogenesis. In a recent investigation $^{32}$ to elucidate the model of assembly of mammalian complex I, NDUFA6 has been proposed to be a part of subcomplex VII, and is thought to associate with the $650 \mathrm{kDa}$ intermediate prior to forming a fully assembled $1 \mathrm{MDa}$ holoenzyme. This is very interesting since all the

Figure 6 Involvement of complex I and ATP in HIV-induced apoptosis. (a) Complex I inhibitor rotenone induces apoptosis in CEM-GFP cells. Cells were treated with 0.3 and $3 \mu \mathrm{M}$ rotenone for $4 \mathrm{~h}$ followed by PE-Annexin staining and analysis by flow cytometry. Values shown are mean of three independent experiments, UT, untreated. (b) Rotenone induces apoptosis in CEM-GFP cells. Cells were treated with 0.3 and $3 \mu \mathrm{M}$ rotenone for $12 \mathrm{~h}$ followed by visualization of DNA fragmentation on $1.8 \%$ agarose gel, UT, untreated. (c) Rotenone sensitivity is reduced in HIV-1-infected cells. Both mock- or HIV-1-infected CEMGFP cells were treated with specific complex I inhibitor rotenone $(3 \mu \mathrm{M})$ or complex V inhibitor oligomycin $(10 \mu \mathrm{g} / \mathrm{ml})$ for $4 \mathrm{~h}$ at different days post-infection, followed by analysis of reduction in cell viability using MTT assay as described in the text. The values are the mean of three independent experiments. (d) HIV-1 infection of CEM-GFP cells lead to reduction in ATP levels. ATP levels were monitored for both mock- and HIV-1-infected CEM-GFP cells at different time points using a luminescent assay described in the text. The data are presented as the relative levels of ATP in infected cells as compared with mock- infected controls. The values are the mean of three independent experiments 


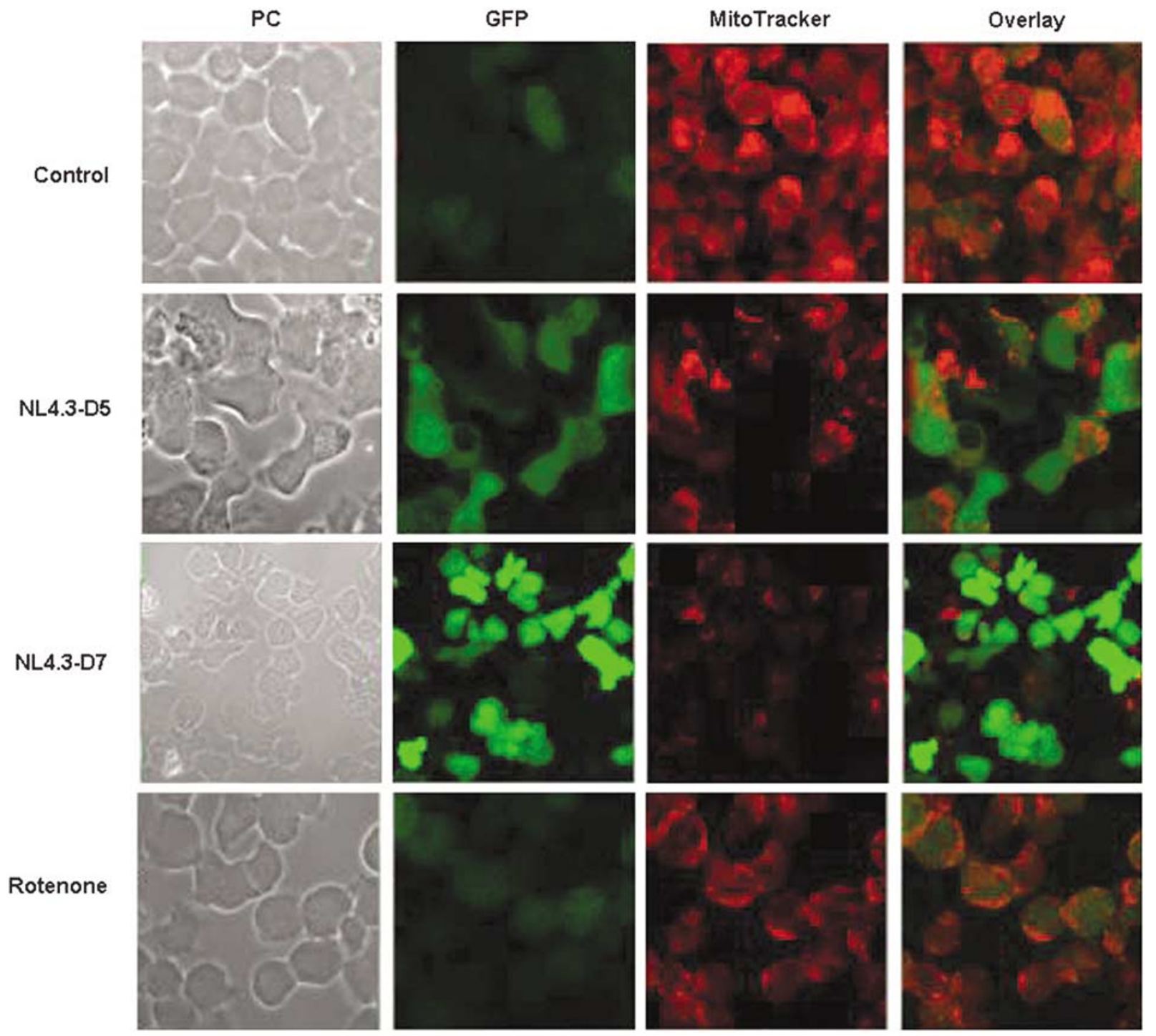

Figure $7 \mathrm{HIV}-1$ reduces the mitochondrial membrane potential of CEM-GFP cells similar to complex I inhibitor rotenone. Analysis of mitochondrial membrane potential was carried out in either mock-infected, NL4.3-infected (days 5 and 7 postinfection) or rotenone-treated $(3 \mu \mathrm{M})$ cells. The cells were stained with Mitotracker (MT) and observed by confocal microscopy for green (GFP) and red (MT) fluorescence. PC, phase contrast image; GFP, GFP expression indicating infection; MitoTracker, staining for $\Delta \Psi_{\mathrm{m}}$ and overlay, GFP and MT overlay

intermediates essentially have to assemble into subcomplex VII prior to forming a fully assembled complex suggesting the importance of this particular subunit. By modulating the expression of NDUFA6 at protein level, HIV-1 reduces the activity of complex I and hence leads to enhanced generation of ROS, decrease in mitochondrial membrane potential and simultaneous decrease in the ATP levels. Although changes in gene expression was not observed for two other complex I subunits tested, it remains to be seen as to what happens with all the other subunits of complex I. It is worth mentioning here that the gene associated with retinoid-interferon-induced mortality 19 (GRIM-19), isolated as a cell death activator was later shown to be a subunit of complex I. ${ }^{36,37}$ Recently, a p75 subunit of complex I, NDUFS1 have been shown to be a critical mitochondrial substrate for caspase- $3^{38}$ pointing again towards an important role for complex I in apoptotic cell death. Based on our present data, induction of apoptosis by HIV could be attributed to the ability of HIV-1 to downregulate complex I activity, which is the entry point of electrons into the ATP-generating system/oxidative phosphorylation and a target of ROS. ${ }^{15}$ Interestingly, sensitivity to complex I inhibitor rotenone is reduced in HIV-1-infected cells indicating an important role for complex I in the cell death induced by HIV. Again induction of apoptosis in NDUFA6 silenced cells and decrease in apoptosis by overexpression of NDUFA6 in HIVinfected cells clearly implicates NDUFA6 and complex I activity in HIV-induced T-cell apoptosis. Thus HIV-1-induced apoptosis involves impairment of the mitochondrial oxidative phosphorylation system although it remains to be seen that whether this is unique to only HIV-induced apoptosis. It would be interesting to study the regulatory mechanism involved in NDUFA6 downregulation and also presence of this phenomenon in already established extrinsic and intrinsic pathways. 
The sequalae of events in HIV-induced apoptosis remains to be elucidated but based on the literature and the present work it can be said that the loss of transmembrane potential due to diminished complex I activity results in generation of ROS and that of PS externalization. ${ }^{39}$ Previously it has been reported that HIV-1 infection does induce ROS production through a mitochondrial pathway. ${ }^{19,40,41}$ Increases in intracellular ROS have also been shown to occur in patients with HIV-1 infection. ${ }^{42,43}$ The present data also indicate that inhibition of complex I activity leads to reduction of ATP levels in HIV-infected cells, but it does not probably lead to complete cessation of ATP synthesis. Since complex II can still channel electrons into the electron transport chain, it can be hypothesized that the ATP levels are maintained at a lower level, by both complex II and reduced complex I activity, to enable the cells to undergo apoptosis. There are numerous evidences to suggest that apoptosis is an ATP-requiring process and that level of ATP or ATP/ADP ratio serves as a marker to differentiate between apoptosis and necrosis. ${ }^{21,44}$ This study further strengthens the previously reported role of ATP in apoptosis and that ATP levels are a sensor for the cell to decide to go for apoptosis or to necrose. In conclusion, the present report not only shows for the first time impairment of complex I activity in HIV-1-induced apoptosis but also provides evidence that this impairment can lead to apoptosis. Finally, the present work identifies a novel viral strategy to downmodulate important cellular activity by targeting a small part of a huge complex.

\section{Materials and Methods}

\section{Cell lines, infection and virus quantitation}

CEM-GFP is a CD4 + T-lymphoblastoid reporter cell line-expressing green fluorescent protein (GFP) under the control of HIV-1 LTR and was obtained from NIH AIDS reagent program. ${ }^{29}$ Jurkat, a CD4 + T-cell line, was obtained from NCCS cell repository, Pune, India. The cells were maintained in RPMI 1640 supplemented with 10\% FCS and PenicillinStreptomycin. CEM-GFP cells were kept under the selection of G418 $(500 \mu \mathrm{g} / \mathrm{ml})$. For each experiment, $5 \times 10^{6}$ CEM-GFP cells were either infected with heat-inactivated (mock infected) or active (infective) NL4.3 virus isolate ${ }^{45}$ at a multiplicity of infection (MOI) of 0.1 in presence of polybrene $(2 \mu \mathrm{g} / \mathrm{ml})$ as described earlier. ${ }^{46}$ Aliquots of cells were removed from mock and HIV-1-infected cells at different time points for further analysis. CEM-GFP cells were also infected with HIV-1 IIIB virus isolate ${ }^{47}$ as described above. Virus production was determined using HIV-1 p24 antigen capture enzyme linked immunosorbent assay (ELISA) of culture supernatants (Perkin Elmer Life Science, USA).

Peripheral blood was collected from normal seronegative donors and PBMC were isolated by Ficoll-Hypaque (Amersham Biosciences, USA) gradient centrifugation. Cells were then activated with $5 \mu \mathrm{g} / \mathrm{ml}$ Phytohemagluttinin for $36-48 \mathrm{~h} .5 \times 10^{6}$ activated PBMCs were then either mock infected or infected with $0.5 \mathrm{MOI}$ of NL4.3 virus for $4 \mathrm{~h}$ in presence of polybrene $(2 \mu \mathrm{g} / \mathrm{ml})$ with intermittent mixing as described earlier. ${ }^{46}$ After washing, the cells were plated in complete medium supplemented with human IL-2 (Roche Applied Bioscience, Germany) at $20 \mathrm{U} / \mathrm{ml}$ concentration and incubated at $37^{\circ} \mathrm{C}$ in a humidified $\mathrm{CO}_{2}$ incubator until the cells were harvested. The infection was monitored by p24 antigen capture ELISA as mentioned earlier.

\section{Flow cytometry}

CEM-GFP cells were initially monitored for infection by visualizing GFP under the fluorescence microscope. Aliquots of mock infected and infected cells were taken at different time points and were stained with PE-Annexin V (BD Pharmingen, USA) according to manufacturer's protocol. GFP fluorescence and Annexin $V$ staining was analyzed on a FACS Vantage flow cytometer (Becton Dickinson, USA).

\section{DNA fragmentation}

Apoptotic DNA laddering was visualized by isolating genomic DNA as described by Park et al. ${ }^{48}$ Briefly, $5 \times 10^{6}$ mock-infected and NL4.3infected CEM-GFP cells were lysed in TE lysis buffer $(10 \mathrm{mM}$ Tris. $\mathrm{HCl}, \mathrm{pH}$ 7.5, $1 \mathrm{mM}$ EDTA, $0.25 \%$ Triton $\mathrm{X}-100$ ) and resuspended by gentle vortexing and incubated at $37^{\circ} \mathrm{C}$ for $20 \mathrm{~min}$. Lysis was followed by RNAse $A$ and proteinase $K$ treatment. 6x DNA loading dye was added to the DNA and analyzed on $1.8 \%$ agarose gel in TBE buffer. The gel was stained with ethidium bromide to visualize DNA fragmentation.

\section{Separation of apoptotic cells from nonapoptotic cells using Annexin beads}

Apoptotic cells were isolated from nonapoptotic cells in the infected cell population using magnetic cell sorting (MACS) technique as per manufacturer's suggestion (Miltenyi Biotec, Germany). $5 \times 10^{7}$ HIV -1 NL4.3-infected CEM-GFP cells were harvested 9 days postinfection and washed with $1 \mathrm{x}$ MACS binding buffer and then incubated with Annexin V magnetic microbeads at $10^{\circ} \mathrm{C}$ for $15 \mathrm{~min}$ with intermittent mixing and then washed with binding buffer. The cells were then loaded on the mini MACS column placed in the magnetic field of a MACS separator. The Annexin Vlabeled apoptotic cells are retained on the column while the unlabeled nonapoptotic cells flow through in washing steps. Apoptotic cells were then collected after removing the column from the magnetic field. Two such rounds of selection were performed to yield more than $90 \%$ pure apoptotic and nonapoptotic cell populations. Nonapoptotic cells and apoptotic cells thus obtained were used for RNA isolation.

\section{Differential display}

Total RNA from the nonapoptotic and apoptotic population was extracted using Trizol reagent (Invitrogen, USA) according to the manufacturer's instructions. Differential expression of genes in these two populations of cells was analyzed by mRNA differential display technique ${ }^{30}$ using RNA Image Kit following manufacturer's protocol (Gene Hunter, USA). The PCR products were resolved on $6 \%$ denaturing polyacrylamidesequencing gel. The differentially expressed gene fragments were eluted from the gel and reamplified using PCR with same primers. The amplified PCR fragments were then cloned into pGEMT-Easy vector (Promega, USA) followed by nucleotide sequencing for identification of genes.

\section{Preparation of mitochondrial fraction}

Mitochondria were isolated using ApoAlert cell fractionation kit following manufacturer's protocol (BD Clontech, USA). $5 \times 10^{7}$ mock-infected and NL4.3-infected cells were collected and centrifuged at $600 \mathrm{~g}$ for $5 \mathrm{~min}$ at $4{ }^{\circ} \mathrm{C}$. After washing, the cell pellet was resuspended in $0.8 \mathrm{ml}$ ice-cold fractionation buffer mix and incubated on ice for $10 \mathrm{~min}$ followed by homogenization in an ice-cold Dounce homogenizer. The homogenate was centrifuged at $700 \mathrm{~g}$ for $10 \mathrm{~min}$. The supernatant was again 
centrifuged at $10,000 \mathrm{~g}$ for $25 \mathrm{~min}$ at $4^{\circ} \mathrm{C}$. Supernatant (cytosol) was collected and the pellet (mitochondria) was resuspended in $50 \mu \mathrm{l}$ of cell fractionation buffer. Purity of the mitochondrial and cytosolic fraction was checked by immunoblotting, using COX-4 and cytochrome $c$ antibody (BD Clontech, USA). Protein concentrations were estimated using Pierce Micro-BCA method following manufacturer's instructions (Pierce, USA).

\section{Reverse transcription PCR}

RNA from nonapoptotic and apoptotic cells was quantitated and used for reverse transcription by MMLV-RT (Invitrogen, USA). The cDNA was amplified by PCR for various genes with Taq polymerase (Invitrogen, USA) using standard conditions and specific oligonucleotide primers as described below:

$\begin{array}{ll}\text { NDUFA6 - } & \text { forward, 5'CAAgATggCggggAgCgg; } \\ \text { NDUFB6 - } & \text { reverse, 5'gTATAgTgAgTTTATTTTgCTC; } \\ \text { forward, 5'TAgTCCgTAgTTCgAggTgCgCC; } & \text { reverse, 5'ggTggATTACTTCTCCAgTCC; } \\ \text { ND2 - } & \text { forward, 5'CTgCATCTACTCTACCATCTTTgC; } \\ \text { Human } \beta \text {-actin - } & \text { reverse, 5'gTTgAgTAgTAggATgCggTAg; } \\ & \text { forward, } \\ & 5^{\prime} \text { TgACggggTCACCCACACTgTgCCCATCTA; } \\ & \text { reverse, } \\ & 5^{\prime} \text { CTAgAACATTTgCggTgACgATggAgg. }\end{array}$

\section{Quantitation of NDUFA6 expression by real-time PCR}

The NDUFA6 expression level was analyzed by quantitative real-time PCR amplification of $c D N A$ in a $25 \mu$ l reaction mixtures containing SYBR green IQ supermix (Bio-Rad, USA) and $10 \mathrm{pmol}$ concentration of each of the HBA or NDUFA6 primer pairs listed above, using ICycler IQ real-time thermal cycler (Bio-Rad, USA). The amplification was performed using one cycle of $95^{\circ} \mathrm{C}$ for $2 \mathrm{~min}$ and 40 cycles of $94^{\circ} \mathrm{C}$ for $1 \mathrm{~min}, 62^{\circ} \mathrm{C}$ for $1 \mathrm{~min}$ and $72^{\circ} \mathrm{C}$ for $1 \mathrm{~min}$ followed by melt curve analysis. The changes in the threshold cycle $\left(C_{T}\right)$ values were calculated by the equation $\Delta C_{T}=C_{T \text { target }}-C_{T \text { input. }}$ The fold differences were calculated as follows: fold difference $=2^{-\Delta\left(\Delta C_{T}\right)}$

\section{Immunoblots}

In all, $100 \mu \mathrm{g}$ of cytosolic and mitochondrial proteins were resolved by SDS-PAGE on $12 \%$ gels and transferred to PVDF membrane (BioRad, USA). Membrane was washed and then blocked in 5\% blocking agent (Amersham, USA). Blots were then probed with specific primary antibodies. Monoclonal antibody against the NDUFA6 and NDUFB6 subunits of complex I was obtained from Molecular Probes, USA. The polyclonal antibody to cleaved PARP was obtained from Promega, USA. HRP-conjugated secondary antibodies (Santacruz Biotech, USA) were used to detect the proteins using ECL plus kit (Amersham, USA) according to the manufacturer's instructions.

\section{Complex I enzyme activity}

Complex I or mitochondrial NADH dehydrogenase activity was assayed using decylubiquinone as electron acceptor as previously described. ${ }^{49}$ Briefly, mitochondrial suspension of infected and uninfected cells was permeabilized using Triton X-100. Assay buffer contained $25 \mathrm{mM}$ potassium phosphate buffer, $\mathrm{pH}$ 8.0, $0.25 \mathrm{mM}$ potassium EDTA, $1 \mathrm{mM}$ $\mathrm{KCN}$ and $100 \mu \mathrm{M} \mathrm{NADH}$. The total assay volume was $1 \mathrm{ml}$. The cuvette containing the assay system was equilibrated to $30^{\circ} \mathrm{C}$ for $3 \mathrm{~min}$ and the reaction was started by addition of $6 \mu \mathrm{l}$ of $10 \mathrm{mM}$ decylubiquinone solution (Molar extinction coefficient at $275 \mathrm{~nm}=12.4 \mathrm{mM}^{-1}$ ). Oxidation of NADH was followed at $340 \mathrm{~nm}$ for $3 \mathrm{~min}$. Using extinction coefficient of $6.22 \mathrm{mM}^{-1}$, the rate was determined with Perkin Elmer Lambda Bio 20 spectrophotometer. The assay was repeated in the presence of specific complex I inhibitor rotenone $(3 \mu \mathrm{M})$. Complex I-specific activity was calculated as the difference between the total activity and that in the presence of rotenone.

\section{Blue native PAGE and in-gel activity staining of complex I}

Complex I activity staining was performed by an in-gel-staining method, wherein $100 \mu \mathrm{g}$ of purified mitochondrial fractions were loaded $(1 \mathrm{~mm}$ thickness plates of Mini Protean III, Biorad, USA) and the complexes were separated on a $5-12 \%$ gradient native polyacrylamide gel (BN-PAGE). Stock solutions for BN-PAGE were $48: 1.5 \%$ polyacrylamide, $10 x$ cathode buffer (500 mM Tricine, $150 \mathrm{mM}$ Bis-Tris-HCl, 0.02\% Coomassie blue G250, pH, 7.0), 3x gel buffer (150 mM Bis-Tris, $1.5 \mathrm{M} \varepsilon$-aminocaproic acid, $\mathrm{pH} 7.0)$ and $10 \mathrm{x}$ anode buffer $(500 \mathrm{mM}$ Bis-Tris- $\mathrm{HCl}, \mathrm{pH} 7.0)$ with a $4 \%$ stacking gel according to modified Schagger's protocol. ${ }^{33}$ Gel electrophoresis was carried out at $40 \mathrm{~V}$ for first half an hour and then at $70 \mathrm{~V}$ to resolve the complexes. Complex I activity was determined immediately by staining the gels with solution containing $2 \mathrm{mM}$ Tris- $\mathrm{HCl}, \mathrm{pH} 7.4,0.1 \mathrm{mg} / \mathrm{ml}$ $\mathrm{NADH}$ and $2.5 \mathrm{mg} / \mathrm{ml}$ Nitro Blue tetrazolium (NBT) for $30 \mathrm{~min}$ to $1 \mathrm{~h}$ at room temperature. ${ }^{50}$

\section{NDUFA6 overexpression in HIV-1-infected Jurkat cells}

Full length NDUFA6 gene (480 bp) was cloned in pTARGET mammalian expression vector (Promega, USA) by RT-PCR using gene-specific primers. Overexpression of NDUFA6 in transfected Jurkat cell using Lipofectamine reagent (Invitrogen, USA) was verified by RT-PCR and Western blot analysis.

In all, $10^{7}$ Jurkat cells were infected with HIV-1 NL4.3 virus at an MOI of 0.2 as described above. On day 3 postinfection, half of the cells were transfected with pTARGET-NDUFA6 using Lipofectamine reagent. Both the untransfected or transfected but infected cells were monitored for apoptosis and NDUFA6 expression by PE-Annexin staining and RT-PCR, respectively, before and after transfection.

\section{SiRNA mediated inhibition of NDUFA6 gene expression}

A total of $2 \times 10^{6}$ Jurkat cells were either mock transfected or transfected with $100 \mathrm{nM}$ of control SiRNA duplex made against nontarget gene, siCONTROL or Smartpool SiRNA duplexes made against NDUFA6 gene (Dharmacon, USA) using Lipofectamine Plus reagent according to manufacturer's instruction (Invitrogen, USA). Cells were harvested 36, 48 and $72 \mathrm{~h}$ post-transfection and assessed for NDUFA6 RNA levels by RT-PCR. The expression levels were further analyzed by real-time PCR using SYBR green supermix and Icycler thermal cycler (BioRad, USA) as described above. The primer sequences used for the real-time PCR were the same as described above. The transfected cells were also stained with PE-Annexin to analyze induction of apoptosis as described earlier. 


\section{Rotenone sensitivity of HIV-1-infected cells}

HIV-1-infected CEM-GFP cells were treated with complex I-specific inhibitor rotenone $(3 \mu \mathrm{M})$ or complex V-specific inhibitor oligomycin $(10 \mu \mathrm{g} / \mathrm{ml})$ for $4 \mathrm{~h}$ on different days postinfection. The cells were then assessed for cell viability and apoptosis using MTT assay and PE-Annexin staining, respectively. Cell viability was determined using colorimetric Cell proliferation Kit I, (Roche Applied Biosciences, Germany) that uses MTT, a tetrazolium salt, which is converted to formazan dye by metabolically active cells. Rotenone-treated cells were also analyzed for apoptosis by PE-Annexin staining followed by flow cytometry.

\section{ATP determination}

ATP measurement of cells was performed using ATP assay kit obtained from Calbiochem, USA, which is based on bioluminescent detection using luciferin-luciferase system. Briefly, equal number of mock-infected and NL4.3-infected CEM-GFP cells were taken in $100 \mu$ l volume in a microtiter plate after thorough mixing. Cells were lysed with the nuclear-releasing buffer for $5 \mathrm{~min}$ at room temperature. ATP monitoring enzyme was added to the cell lysate. The sample was read in the Packard Topcount Microplate Counter for $1 \mathrm{~min}$. Percent decrease in the ATP levels was determined by comparing the results with the levels of mock-infected control cells in a multiday experiment.

\section{Membrane potential studies by confocal microscopy}

MitoTracker Red CMXRos (Molecular Probes, USA) is a red-fluorescent dye that stains mitochondria in live cells and its accumulation is dependent upon mitochondrial membrane potential. Decrease in staining of the cells with MitoTracker Red (MT) indicates loss of mitochondrial membrane potential. Either control (mock-infected), rotenone-treated $(3 \mu \mathrm{M})$ or NL4.3-infected (days 5 and 7) CEM-GFP cells were stained with MT at $200 \mathrm{nM}$ final concentration according to standard protocol. The cells were then fixed and spun on a glass slide at $500 \mathrm{rpm}$ for $2 \mathrm{~min}$ to obtain a monolayer of cells and mounted using mounting media (Sigma, USA). The cells were stored in dark until visualized by a confocal microscope (Zeiss LSM 410 microscope, Germany). The cells were observed for GFP expression and MT staining (Excitation, $579 \mathrm{~nm}$; Emission, $599 \mathrm{~nm}$ ). The increase in green fluorescence was indicative of HIV-1 infection and decrease in red fluorescence was indicator of loss in mitochondrial membrane potential. The images were captured in green, red and phase contrast channel and the overlay was taken for green and red fluorescence.

\section{Acknowledgements}

We are thankful to Dr. GC Mishra, Director, NCCS for his support and constant encouragement and Dr. A Sahu, Dr. V Prasad and Dr. K Ganjam for critically reading the manuscript. We thank DS Ravi, M Kumar and DH Dandekar for their technical help and the NCCS FACS facility for flow cytometry. We also thank Dr. Saibal Dey and Dr. Hana Antonicka for their valuable help in the present study. This work was supported by Department of Biotechnology, Govt. of India. JSL is a senior research fellow and MKT is a junior research fellow of Council of Scientific and Industrial Research, Govt. of India.

\section{References}

1. Herbein G, Van Lint C, Lovett JL and Verdin E (1998) Distinct mechanisms trigger apoptosis in human immunodeficiency virus type 1-infected and in uninfected bystander T lymphocytes. J. Virol. 72: 660-670

2. Badley AD, Pilon AA, Landay A and Lynch DH (2000) Mechanisms of HIVassociated lymphocyte apoptosis. Blood 96: 2951-2964

3. Lenardo MJ, Angleman SB, Bounkeua V, Dimas J, Duvall MG, Graubard MB, Hornung F, Selkirk MC, Speirs CK, Trageser C, Orenstein JO and Bolton DL (2002) Cytopathic killing of peripheral blood CD4 (+) T lymphocytes by human immunodeficiency virus type 1 appears necrotic rather than apoptotic and does not require env. J. Virol. 76: 5082-5093

4. Alimonti JB, Ball TB and Fowke KR (2003) Mechanisms of CD4+ T lymphocyte cell death in human immunodeficiency virus infection and AIDS. J. Gen. Virol. 84: 1649-1661

5. Stevenson M (2003) HIV-1 pathogenesis. Nat. Med. 9: 853-860

6. Roshal M, Zhu $Y$ and Planelles V (2001) Apoptosis in AIDS. Apoptosis 6: 103-116

7. Ross TM (2001) Using death to one's advantage: HIV modulation of apoptosis. Leukemia 15: 332-341

8. Gougeon ML (2003) Apoptosis as an HIV strategy to escape immune attack. Nat. Rev. Immunol. 3: 392-403

9. Finkel TH, Tudor-Williams G, Banda NK, Cotton MF, Curiel T, Monks C, Baba TW, Ruprecht RM and Kupfer A (1995) Apoptosis occurs predominantly in bystander cells and not in productively infected cells of HIV- and SIV-infected lymph nodes. Nat. Med. 1: 129-134

10. Carbonari M, Pesce AM, Cibati M, Modica A, Dell'Anna L, D'Offizi G, Angelici A, Uccini S, Modesti A and Fiorilli M (1997) Death of bystander cells by a novel pathway involving early mitochondrial damage in human immunodeficiency virus-related lymphadenopathy. Blood 90: 209-216

11. Perl A, Gergely Jr P, Puskas F and Banki K (2002) Metabolic switches of T-cell activation and apoptosis. Antioxid. Redox Signal. 4: 427-443

12. Newmeyer DD and Ferguson-Miller S (2003) Mitochondria: releasing power for life and unleashing the machineries of death. Cell 112: 481-490

13. Kroemer G, Zamzami N and Susin SA (1997) Mitochondrial control of apoptosis. Immunol. Today 18: 44-51

14. Perl A and Banki K (2000) Genetic and metabolic control of the mitochondrial transmembrane potential and reactive oxygen intermediate production in HIV disease. Antioxid. Redox. Signal. 2: 551-573

15. Ricci JE, Waterhouse N and Green DR (2003) Mitochondrial functions during cell death, a complex (I-V) dilemma. Cell Death Differ. 10: 488-492

16. Green DR and Kroemer G (2004) The pathophysiology of mitochondrial cell death. Science 305: 626-629

17. Badley AD, Roumier T, Lum JJ and Kroemer G (2003) Mitochondrion mediated apoptosis in HIV-1 infection. Trends Pharmacol. Sci. 24: 298-305

18. Cossarizza A, Troiano L and Mussini $C$ (2002) Mitochondria and HIV infection: the first decade. J. Biol. Regul. Homeost. Agents 16: 18-24

19. Banki K, Hutters E, Gonchoroff NJ and Perl A (1998) Molecular ordering in HIVinduced apoptosis. J. Biol. Chem. 273: 11944-11953

20. Franko J, Pomfy M and Prosbova T (2000) Apoptosis and cell death (mechanisms, pharmacology and promise for the future). Acta Medica (Hradec Kralove) 43: 63-68

21. Richter C, Schweizer M, Cossarizza A and Franceschi C (1996) Control of apoptosis by the cellular ATP level. FEBS Lett. 378: 107-110

22. Ricci JE, Gottlieb RA and Green DR (2003) Caspase-mediated loss of mitochondrial function and generation of reactive oxygen species during apoptosis. J. Cell Biol. 160: 65-75

23. Selliah N, Shackelford J, Wang J-F, Traynor F, Yin J and Finkel TH (2003) T cell signaling and apoptosis in HIV disease. Immunol. Res. 27: 247-260

24. Scheuring UJ, Corbeil J, Mosier DE and Theofilopoulos AN (1998) Early modification of host cell gene expression induced by HIV-1. AIDS 12: 563-570

25. Ryo A, Suzuki Y, Ichiyama K, Kondoh N, Wakatsuki T, Hada A, Yamamoto M and Yamamoto N (1999) Serial analysis of gene expression in HIV-1-infected T cell lines. FEBS Lett. 462: 182-186

26. Geiss GK, Bumgarner RE, An MC, Agy MB, Van't Wout A, Hammersmark E, Carter VS, Upchurch D, Mullins JI and Katze MG (2000) Large-scale monitoring of host cell gene expression during HIV-1 infection using CDNA microarrays. Virology 266: 8-16 
27. Corbeil J, Sheeter D, Genini D, Rought S, Leoni L, Du P, Ferguson M, Masys DR, Welsh JB, Fink JL, Sasik R, Huang D, Drenkow J, Richman DD and Gingeras T (2001) Temporal gene regulation during HIV-1 infection of human CD4+ T cells. Genome Res. 11: 1198-1204

28. Van't wout A, Lehrman GK, Mikheeva SA, O'keeffe GC, Katze MG, Bumgarner GE, Geiss GK and Mullins JI (2003) Cellular gene expression upon human immunodeficiency virus type 1 infection of CD4 (+) T-cell lines. J. Virol. 77: 1392-1402

29. Gervaix A, West D, Leoni LM, Richman DD, Wong-Staal F and Corbeil J (1997) A new reporter cell line to monitor HIV infection and drug susceptibility in vitro. Proc. Natl. Acad. Sci. USA 94: 4653-4658

30. Liang $P$ and Pardee $A B$ (1992) Differential display of eukaryotic messenger RNA by means of the polymerase chain reaction. Science 257: 967-971

31. Ton C, Hwang DM, Dempsey AA and Liew CC (1997) Identification and primary structure of five human NADH-Ubiquinone Oxidoreductase subunits. Biochem. Biophys. Res. Commun. 241: 589-594

32. Antonicka H, Ogilvie I, Taivassalo T, Anitori RP, Haller RG, Vissing J, Kennaway NG and Shoubridge EA (2003) Identification and characterization of a common set of complex I assembly intermediates in mitochondria from patients with complex I deficiency. J. Biol. Chem. 278: 43081-43188

33. Schagger H, Bentlage H, Ruitenbeek W, Pfeiffer K, Rotter S, Rother C, Bottcher-Purkl A and Lodemann E (1996) Electrophoretic separation of multiprotein complexes from blood platelets and cell lines: technique for the analysis of diseases with defects in oxidative phosphorylation. Electrophoresis. 17: 709-714

34. Wolvetang EJ, Johnson KL, Krauer K, Ralph SJ and Liannane AW (1994) Mitochondrial respiratory chain inhibitors induce apoptosis. FEBS Lett. 339 40-44

35. Li N, Ragheb K, Lawler G, Sturgis J, Rajwa B, Melendez AJ and Robinson PJ (2003) Mitochondrial complex I inhibitor rotenone induces apoptosis through enhancing mitochondrial reactive oxygen species production. J. Biol. Chem. 278: 8516-8525

36. Angell JE, Lindner DJ, Shapiro PS, Hofmann ER and Kalvakolanu DV (2000) Identification of GRIM-19, a novel cell death-regulatory gene induced by the interferon-beta and retinoic acid combination, using a genetic approach. J. Biol. Chem. 275: 33416-33426

37. Fearnley IM, Carroll J, Shannon RJ, Runswick MJ, Walker JE and Hurst J (2001) Grim-19, a cell death regulatory gene product, is a subunit of bovine mitochondrial NADH: ubiquinone oxidoreductase (complex I). J. Biol. Chem. 276: 38345-38348

38. Ricci JE, Munoz-Pinedo C, Fitzgerald P, Bailly-Maitre B, Perkins GA, Yadava $\mathrm{N}$, Scheffler IE, Ellisman MH and Green DR (2004) Disruption of mitochondrial function during apoptosis is mediated by caspase cleavage of the p75 subunit of complex I of the electron transport chain. Cell 117: 773-786

39. Zamzami N, Marchetti P, Castedo M, Decaudin D, Macho A, Hirsch T, Susin SA, Petit PX, Mignotte B and Kroemer G (1995) Sequential reduction of mitochondrial transmembrane potential and generation of reactive oxygen species in early programmed cell death. J Exp Med. 182: 367-377

40. Macho A, Castedo M, Marchetti P, Aguilar JJ, Decaudin D, Zamzami N, Girard PM, Uriel J and Kroemer G (1995) Mitochondrial dysfunctions in circulating $T$ lymphocytes from human immunodeficiency virus-1 carriers. Blood. 86: 2481-2487

41. Gill L, Martinez G, Gonzalez I, Tarinas A, Alvarez A, Giuliani A, Molina R, Tapanes R, Perez J and Leon OS (2003) Contribution to characterization of oxidative stress in HIV/AIDS patients. Pharmocol. Res. 47: 217-224

42. Kruman II, Nath A and Mattson P (1998) HIV-1 protein tat induces apoptosis of hippocampal neurons by a mechanism involving caspase activation, calcium overload and oxidative stress. Exp. Neurol. 154: 276-288

43. Elbim C, Pillet S, Prevost MH, Preira A, Firard PM, Rogine N, Matusani H, Hakim J, Israel N and Gougerot-Pocidalo MA (1999) Redox and activation status of monocytes from human immunodeficiency virus-infected patients: relationship with viral load. J. Virol. 73: 4561-4566

44. Nicotera P, Leist M and May EF (1998) Intracellular ATP, a switch in the decision between apoptosis and necrosis. Toxicol lett. 102-103: 139-142

45. Adachi A, Gendelman HE, Koenig S, Folks T, Wiley R, Rabson A and Martin MA (1986) Production of acquired immunodeficiency syndrome-associated retrovirus in human and nonhuman cells transfected with an infectious molecular clone. J. Virol. 59: 284-291

46. Mitra D, Steiner M, Lynch DH, Staiano-Coico L and Laurence J (1996) HIV-1 upregulates Fas ligand expression in CD4+ $\mathrm{T}$ cells in vitro and in vivo: association with Fas-mediated apoptosis and modulation by aurintricarboxylic acid. Immunology 87 : 581-585

47. Popovic M, Sarngadharan MG, Read E and Gallo RC (1984) Detection, isolation, and continuous production of cytopathic retroviruses (HTLV-III) from patients with AIDS and pre-AIDS. Science 224: 497-500

48. Park DJ and Patek PQ (1998) Detergent and enzyme treatment of apoptotic cells for the observation of DNA fragmentation. Biotechniques 24: 558-560

49. Parker Jr WD, Parks J, Filley CM and Kleinschmidt-DeMasters BK (1994) Electron transport chain defects in Alzheimer's disease brain. Neurology 44: 1090-1096

50. Jung C, Higgins CMJ and Xu Z (2000) Measuring the quantity and activity of mitochondrial electron transport chain complexes in tissues of central nervous system using blue native polyacrylamide gel electrophoresis. Anal. Biochem. 286: 214-223

Supplementary Information accompanies the paper on Cell Death and Diffrentiation website (http://www.nature.com/cdd). 